\title{
Nonlinear Adjustment to Purchasing Power Parity in the post-Bretton Woods Era
}

\author{
Christopher F. Baum ${ }^{1}$ \\ Department of Economics \\ Boston College \\ John T. Barkoulas \\ Department of Economics and Finance \\ Louisiana Tech University \\ Mustafa Caglayan \\ Department of Economics and Finance \\ University of Durham, UK
}

\begin{abstract}
This paper models the dynamics of adjustment to long-run PPP over the post-Bretton Woods period in a nonlinear framework consistent with the presence of frictions in international trade. We estimate exponential smooth transition autoregressive (ESTAR) models of deviations from PPP, which are obtained using the Johansen cointegration method, for both CPI- and WPIbased measures and a broad set of U.S. trading partners. In several cases, we find clear evidence of a mean-reverting dynamic process for sizable deviations from PPP, with the equilibrium tendency varying nonlinearly with the magnitude of disequilibrium. Analysis of impulse response functions also supports a nonlinear dynamic structure, but convergence to long-run PPP in the post-Bretton Woods era is very slow.
\end{abstract}

JEL: F32, C22. Keywords: purchasing power parity, ESTAR, cointegration.

1 Corresponding author: Christopher F. Baum, Department of Economics, Boston College, Chestnut Hill, MA 02467 USA, Tel: 617-552-3673, fax 617-552-2308, e-mail: baum@bc.edu. 


\section{Introduction}

The doctrine of purchasing power parity (PPP) in its absolute form states that a common basket of goods, when quoted in the same currency, costs the same in all countries. ${ }^{1}$ The parity condition rests on the assumption of perfect inter-country commodity arbitrage and is a central building block of many theoretical and empirical models of exchange rate determination. ${ }^{2}$ Due to factors like transaction costs, taxation, subsidies, actual or threatened trade restrictions, the existence of nontraded goods, imperfect competition, foreign exchange market interventions, and the differential composition of market baskets and price indices across countries, one may expect PPP to be valid only in the long-run.

Empirical studies over long periods have supported long-run PPP (Diebold et al. (1991), Taylor (1996), Michael et al. (1997)). However, results are mixed when the recent floating-rate period is examined. Using standard unit-root tests, Corbae and Ouliaris (1988), Meese and Rogoff (1988), Edison and Fisher (1991), and Grilli and Kaminsky (1991) cannot reject the unit-root null hypothesis for real exchange rates in the managed-float regime. In contrast, Pedroni (1995), Frankel and Rose (1996), Lothian (1997), Oh (1996), Wu (1996), and Papell and Theodoridis (1998) find strong evidence of mean reversion in real exchange rates by implementing panel data variants of standard unit-root tests. $^{3}$ However, O'Connell (1998a) strongly disputes these mean-reversion findings in real exchange rates as they fail to control for cross-sectional dependence in the data. ${ }^{4}$ Additional evidence against reversion to PPP based on a panel of real exchange

\footnotetext{
1 Relative PPP, which is implied by absolute PPP, states that the growth rate in the nominal exchange rate equals the differential between the growth rates in home and foreign price indices.

2 See Rogoff (1996) and Froot and Rogoff (1995) for a review of the literature on PPP.

3 Employing an alternative multivariate unit-root test where the null hypothesis is nonstationarity of at least one of the series under consideration, Taylor and Sarno (1998) find strong support for mean reversion in a panel of CPI-based U.S. dollar exchange rates of the G5 countries. However, their evidence is not supportive of mean reversion for GNP deflator- and PPI-based real exchange rates for the same panel of countries. Taylor and Sarno also point to a number of pitfalls when using panel unit-root tests.

4 See Higgins and Zakrajsek (1999) for evidence contrary to that of O'Connell's.
} 
rates is reported in Engel et al. (1997). Papell (1997) and Liu and Maddala (1996) also find that evidence of mean reversion in panels of real exchange rates is very sensitive to the groups of countries considered. ${ }^{5}$

Recently, an alternative explanation bases the persistence of managed-float deviations from parity on the presence of market frictions that impede commodity trade. Dumas (1992), Uppal (1993), Sercu et al. (1995), and Coleman (1995) develop equilibrium models of real exchange rate determination which take into account transactions costs and show that adjustment of real exchange rates toward PPP is necessarily a nonlinear process. ${ }^{6}$ Market frictions in international trade introduce a neutral range, or band of inaction, within which deviations from PPP are left uncorrected, as they are not large enough to cover transactions costs. Only deviations outside the neutral range are arbitraged away by market forces. In this dynamic equilibrium framework, deviations from PPP follow a nonlinear stochastic process that is mean-reverting.

In an initial test of the hypothesis of the analytic work of PPP adjustment process based on market frictions, Michael et al. (1997) apply an exponential smooth transition autoregression (ESTAR) model to two data sets-a two-century span of annual data and a monthly sample of interwar observations-and find strong support for the nonlinear representation. ${ }^{7}$ Subsequently, using threshold autoregression modelling, Obstfeld and Taylor (1997) and O'Connell and Wei (1997) report additional evidence of nonlinear price adjustment induced by the presence of transaction costs. ${ }^{8}$ However, O'Connell (1998b), utilizing an equilibrium threshold autoregression (TAR) model to post-Bretton Woods real exchange rates in a panel framework, finds little support to a market-frictions

\footnotetext{
5 A summary of stylized facts regarding real exchange rate behavior in the post-Bretton Woods era is presented in Lothian (1998).

$6 \quad$ Instead of assuming instantaneous trade, Coleman considers the case in which time elapses when goods are shipped between markets.

7 Goldberg et al. (1997) derive a nonlinear "mean reverting elastic random walk toward a stochastic PPP rate" and find that the mean-reversion process is not linear for some countries.

8 Obstfeld and Taylor detect 'band reversion' for price differentials of disaggregated as well as aggregated CPIs for thirty-two city and country locations during the 1980-1985 period. O'Connell and Wei report mean reversion (to the equilibrium value of zero) for price-parity deviations for forty-eight final goods and services for twenty-four U.S. cities during the 1975-1992 period.
} 
explanation for the persistence of PPP deviations. ${ }^{9}$

In this study, we contribute to the literature on transactions cost-based nonlinear price adjustment mechanisms under the current float at two levels. First, we estimate the deviations series from PPP using cointegration analysis, rather than imposing the strict PPP $(1,1,-1)$ cointegrating vector in calculating real exchange rates. Strong PPP might not hold due to differential composition of price indices across countries (Patel (1990)), differential productivity shocks (Fisher and Park (1991)), and measurement errors in prices as a result of aggregation and index construction (Taylor (1988), Cheung and Lai (1993)). This latter rationale is very compelling, since available price indices are likely to be flawed approximations to the theoretical constructs underlying PPP. ${ }^{10}$ These analytical justifications which explain why the cointegrating vector between nominal exchange rates and prices may vary greatly across countries have received strong empirical support. The data in several studies (e.g. Pedroni (1997) and Li (1999)) strongly reject the symmetry and proportionality restrictions required for strict PPP. As a second contribution, we employ the ESTAR framework to analyze the dynamic behavior of deviations from PPP, which may be advantageous relative to the standard TAR framework in which regime changes occur abruptly. Consistent with Teräsvirta (1994), if an aggregated process is observed, which is the case with our data set here, regime changes may be smooth rather than discrete as long as heterogeneous economic agents do not act simultaneously (which is unlikely) even if they individually make dichotomous decisions. Additionally, in the analytics by Dumas (1992) and others, the adjustment process to parity is smooth rather than discrete.

We apply the ESTAR methodology to a sample of post-Bretton Woods monthly data for a broad set of U.S. trading partners: seventeen countries' CPI-based measures and eleven countries' WPI-based measures. Deviations from the presumed long-run PPP

\footnotetext{
9 With the exception of a panel consisting of six European Union countries, his evidence is statistically insignificant at the five percent level. His threshold autoregression results are also statistically insignificant on a country-by-country basis.

10 See Cheung and Lai (1993) for a proof that the presence of measurement errors in the observed price levels of output results in a non-unit cointegrating vector in the PPP cointegrating regression.
} 
relationship are estimated using the Johansen cointegration methodology. An ESTAR model is then applied to those deviations for which the linearity hypothesis is rejected. The Johansen cointegration evidence provides ample support for "weak" PPP over this expanded sample period of the managed exchange-rate regime. Moreover, we find that an ESTAR model is appropriate for seven (five) of these countries when CPIs (WPIs) are used to measure prices for foreign and domestic outputs. Nonlinear adjustment of PPP deviations in the post-Bretton Woods era dominates a linear specification for several of the trading partners studied and the ESTAR model's estimated parameters support mean reversion for sizable PPP deviations for these countries. Generalized impulse response functions for the estimated models demonstrate that the dynamic response of deviations from PPP to innovations varies nonlinearly with their magnitude, which highlights the importance of nonlinear modelling of these dynamics. Our results are generally consistent with Michael et al.'s results from a small set of countries over an earlier period. In our post-Bretton Woods sample, the range of the estimated transition function values indicates that convergence back to PPP is very slow.

The rest of the paper is constructed as follows. Section 2 reviews the rationale for nonlinear adjustment and presents the nonlinear model to be estimated. Section 3 presents the data and the empirical estimates. Section 4 concludes with a summary of the evidence.

\section{Nonlinear Adjustment toward PPP}

\subsection{The ESTAR model of deviations from PPP}

In a framework of dynamic equilibrium in spatially separated markets, Dumas (1992), Uppal (1993), Sercu et al. (1995), and Coleman (1995) show that the presence of transaction costs in international trade implies that deviations from PPP converge to parity in a 
nonlinear fashion. Transaction costs create a band of inaction within which international price differentials are not arbitraged away; only price differentials exceeding transaction costs (outside the band) are profitable to arbitrage. Transaction costs must be overcome for trade in goods to take place, as they play the role of the bid-ask spread in no-arbitrage models of financial markets. More specifically, Dumas' (1992) model considers the case of two countries producing one homogeneous good that can be consumed, invested, or transferred abroad. Both countries are endowed with identical production technologies but with uncorrelated output (productivity) shocks. Transferring goods and/or physical capital from one country to another is costly: if one unit of a good is shipped, only $(1-s), s \in(0,1)$, of that good actually arrives. Risk averse agents solve for joint equilibrium in the goods and capital markets to obtain the capital transfers between the countries (balance of trade), consumption, investment, and the real exchange rate (the relative price of physical capital between the two countries). It is optimal for agents to rebalance the stock of goods after each random output shock. However, in the presence of transaction costs, no rebalancing will occur until the marginal benefit of rebalancing exceeds its marginal cost. The no-arbitrage band, in which no shipping occurs, is given for (logarithms of) real exchange rate values in the range $\left[s, s^{-1}\right]$. Therefore, in equilibrium under rational expectations the real exchange rate can deviate from its parity value of unity. In this framework, the real exchange rate exhibits mean reversion for large deviations from PPP, but "spends most of the time away from parity..." (Dumas (1992), p.154).

To model the behavior of the real exchange rate in this nonlinear context, we must specify a structure which may be considered a generalization of the standard linear model and which may be estimated from the available data. In the standard Engle-Granger (1987) linear cointegration methodology, the speed of adjustment to restore equilibrium is independent of the magnitude of disequilibrium. Other approaches, such as Balke and Fomby's (1997) threshold cointegration methodology, require the estimation of discrete thresholds separating a central regime (in which no adjustment, or in the PPP framework, 
no trade takes place) from 'outer' regimes in which equilibrating forces appear. This discrete threshold methodology may be quite appropriate in the context of an explicit band, such as the EMS exchange rate mechanism. However, the empirical effects of transaction costs in international trade will vary, depending upon the mix of goods exported and imported by a pair of trading partners. Moreover, outside the analytical structure of a two-country, one-good world, the specification of fixed transaction costsand thus fixed thresholds-becomes problematic. Also, as long as heterogeneous economic agents (who individually make dichotomous decisions) do not act simultaneously, regime changes at an aggregated level may be smooth rather than discrete.

These considerations led Michael et al. (1997) to apply a particular form of the 'smooth transition' threshold autoregressive (STAR) model. In the STAR framework, the fixed thresholds of a standard threshold autoregressive (TAR) model are replaced with a smooth function, which need only be continuous and non-decreasing (Tong (1993), p. 108). The need for symmetry in the response to positive and negative deviations from PPP leads to the exponential STAR, or ESTAR model described by Teräsvirta (1994). The ESTAR model can be viewed as a generalization of the double-threshold TAR model. It is particularly attractive in the present context, as the strength of the equilibrating force is increasing in the (absolute) magnitude of the degree of disequilibrium, in line with predictions from the analytics of Dumas and others. Their framework, in which "...longrun behavior is very different from short-run behavior..." (Dumas (1992), p. 171), is poorly approximated by the constant speed of adjustment of the linear cointegration framework, compared to the flexible nature of the ESTAR approach. In this context, the ESTAR model will be more suitable than the TAR framework in analyzing the dynamic behavior of the deviations from PPP.

In the ESTAR model applied to deviations from PPP $\left(y_{t}\right)$, the transition function $\mathrm{F}\left(y_{t-d}\right)$, a U-shaped relation, determines the speed of the transition process. In its general form, $\mathrm{F}\left(y_{t-d}\right)=1-\exp \left[\frac{-\gamma\left(y_{t-d}-c^{*}\right)^{2}}{\hat{\sigma}_{y_{t}}^{2}}\right] \cdot{ }^{11}$ The transition function is a component

11 The argument of the exponential is scaled by the sample variance of the transition variable following the suggestion 
of the general ESTAR specification:

$$
y_{t}=k+\sum_{j=1}^{p} \pi_{j} y_{t-j}+\left(k^{*}+\sum_{j=1}^{p} \pi_{j}^{*} y_{t-j}\right) \times F(\cdot)+\epsilon_{t}
$$

When $y_{t-d}=c^{*}$, its equilibrium value, $\mathrm{F}(\cdot)=0$ and the model reverts to a standard linear $A R(p)$ representation. For extreme deviations from $\mathrm{PPP}, \mathrm{F}(\cdot)=1$, and (1) becomes a different $A R(p)$ model, with intercept $k+k^{*}$ and $\mathrm{j}^{\text {th }}$-order term $\pi_{j}+\pi_{j}^{*}$. The transition between these regimes is smooth, in that as $\left|y_{t-d}\right|$ increases in magnitude, the behavior of $y_{t}$ becomes more dependent upon the starred coefficients' values. In the analysis to follow, a convenient reparameterization of the model in (1) is implemented, as given by:

$$
\Delta y_{t}=k+\lambda y_{t-1}+\sum_{j=1}^{p-1} \varphi_{j} \Delta y_{t-j}+\left(k^{*}+\lambda^{*} y_{t-1}+\sum_{j=1}^{p-1} \varphi_{j}^{*} \Delta y_{t-j}\right) \times F(\cdot)+\epsilon_{t}
$$

As should be evident, this model reverts to a linear specification in the absence of nonlinearity, that specification being the standard augmented Dickey-Fuller regression which would be estimated in testing for stationarity of the equilibrium error (in our case, deviations from PPP). That model can be represented as:

$$
\Delta y_{t}=k^{\prime}+\lambda^{\prime} y_{t-1}+\sum_{j=1}^{p-1} \varphi_{j}^{\prime} \Delta y_{t-j}+\epsilon_{t}
$$

If model (2) is the correct specification, the ADF model (3) will estimate the parameter $\lambda^{\prime}$ as some combination of $\lambda$ and $\lambda^{*}$, and the model's estimate of the impact of the lagged level $y_{t}$ will be inconsistent due to misspecification (essentially, the omitted variables in the bracketed portion of (2)). In the ESTAR model, the coefficient $\lambda$ will govern the adjustment process for small deviations from PPP, whereas when deviations are sizable, and $\mathrm{F}(\cdot)$ approaches unity, the $\lambda^{*}$ coefficient becomes more and more important. The least squares estimation algorithm and makes it possible to compare estimates of $\gamma$ across equations. 
quantity $\left(\lambda+\lambda^{*}\right)$ must be negative to ensure global stability and mean reversion in the 'outer' regime. For small deviations from PPP, however, random-walk behavior is admissible: that is, $\lambda$ may even be positive, implying explosive dynamic behavior, as long as it does not exceed $\lambda^{*}$ in absolute value.

\subsection{Test procedures}

Two tests are performed on the components of each country's real exchange rate to determine whether that series should be included in the multivariate ESTAR model. First, a linear cointegration test is conducted, using the Johansen methodology. Conditional on the estimated disequilibrium series obtained from the Johansen method, the second test applies the artificial regression developed by Teräsvirta (1994) to test for linearity versus an ESTAR specification. In its general form, this regression takes the form:

$$
y_{t}=\beta_{o o}+\sum_{j=1}^{p}\left(\beta_{0 j} y_{t-j}+\beta_{1 j} y_{t-j} y_{t-d}+\beta_{2 j} y_{t-j} y_{t-d}^{2}\right)+\eta_{t}
$$

In this regression, rejection of the null hypothesis $\beta_{1 j}=\beta_{2 j}=0$ for all $j$ provides evidence of nonlinearities. The order of the autoregression, $p$, is chosen on the basis of serial correlation tests on the residual vectors from alternative autoregressive representations of $y_{t}$. As Teräsvirta (1994) points out, neglected autocorrelation structure may lead to false rejections of the linearity hypothesis in favor of the presence of nonlinearities. He also warns against the usage of automatic selection criteria for choosing the autoregressive lag order without testing for residual autocorrelation.

Given the choice of $p$, the delay length $(d)$ is varied in order to provide the strongest discrimination, and the $d$ corresponding to the smallest $\mathrm{P}$-value for the hypothesis test is chosen. ${ }^{12}$ Rejection of this null hypothesis implies that the standard linear cointegration test may fail to reject its null of no linear cointegration due to the presence of nonlineari-

\footnotetext{
12 We considered delay length up to 12 months, as it was apparent from the data that longer delay orders than the 3 months considered by Michael et al. were preferred.
} 
ties in $y_{t}$. If nonlinearities are present, they imply that the linear cointegrating regression is misspecified, providing a rationale for findings that fail to support the theory of PPP as a long-run equilibrium concept.

\subsection{Parameter restrictions on the ESTAR model}

In this application of the ESTAR model, the nature of $y_{t}$ as the mean-corrected deviations from PPP, estimated using the residuals of the cointegrating regression, implies that the constant terms in (2) may be expected to equal zero. Similarly, the equilibrium value of $y_{t}$ in the model, $c^{*}$, should also equal zero. Given zero values for those three parameters, further restrictions consistent with this application of ESTAR are $\lambda^{*}=-(1+\lambda)$ and $\varphi_{j}=-\varphi_{j}^{*},(j=1, \ldots, p-1)$ which imply that when deviations from PPP are large, the $y_{t}$ process will be white noise. Conditional on those restrictions, one may test whether $\lambda=0$. Failure to reject this latter hypothesis would provide support for unit-root behavior for small deviations from PPP, with mean-reverting adjustment taking place for large deviations. If all three sets of restrictions may be applied, the ESTAR specification simplifies considerably. The estimates presented below embody the restrictions which cannot be rejected by the data.

\section{$3 \quad$ Data and Empirical Estimates}

\subsection{Data}

The PPP hypothesis can be tested by estimating the regression

$$
S_{t}=\beta_{0}-\beta_{1} P_{t}+\beta_{2} P_{t}^{*}+\varepsilon_{t}
$$

where $\beta_{0}$ is some constant, $S_{t}$ is the logarithm of the foreign price of domestic currency at 
time $t, P_{t}$ and $P_{t}^{*}$ are the logarithms of the domestic and foreign price levels, respectively, at time $t$, and $\varepsilon_{t}$ is a disturbance term capturing deviations from PPP at time $t$. Both the consumer price index (CPI) and the wholesale price index (WPI) are used as proxies for measuring price levels of each country's output.The nominal exchange rates are endof-month bilateral U.S. dollar exchange rates. In all cases, the U.S. is considered the home country.

All series are extracted from the International Monetary Fund's International Financial Statistics database and span the period August 1973 to December 1995: a total of 269 monthly observations. PPP analysis based on CPI measures of prices is implemented for seventeen countries: Canada, Germany, United Kingdom, France, Italy, Japan, Belgium, Denmark, Luxembourg, Netherlands, Norway, Sweden, Switzerland, Finland, Greece, Portugal, and Spain. Using the WPI measure of prices, PPP analysis is implemented for eleven of the seventeen countries (excluding France, Italy, Belgium, Luxembourg, Switzerland, and Portugal).

\subsection{Tests for cointegration}

The validity of the PPP hypothesis as a long-run equilibrium concept requires that $\varepsilon_{t}$ in (5) be a stationary process, that is, the system variables $\left(S_{t}, P_{t}, P_{t}^{*}\right)$ should form a cointegrated system (Engle and Granger (1987)). The strict (absolute) version of PPP requires that the cointegrating vector be $(1,1,-1)$, imposing the joint restrictions of symmetry $\left(\beta_{1}=\beta_{2}\right)$ and proportionality $\left(\beta_{1}=\beta_{2}=1\right)$. However, as discussed above, these restrictions may not be consistent with the empirical evidence due to measurement errors in prices, differential composition of price indices across countries, and differential productivity shocks.

The PPP relationship in (5) is estimated using the Johansen method (Johansen (1988), Johansen and Juselius (1990)), a reduced rank regression technique. ${ }^{13}$ The Johansen

13 All system variables have been tested for the presence of a unit root using the Augmented Dickey-Fuller and 
method employs a VAR framework which incorporates both the short- and long-run dynamics of the system. The lag length of the VAR model for each country is determined using the multivariate Akaike information criterion (AIC) allowing for a maximum lag length of twelve. ${ }^{14}$ Given the optimal choice of lag length for each country, the estimated residual vectors from each system equation are tested for serial correlation up to order twenty-four. If the residual vector from any of the system equations is serially correlated, the lag length of the VAR is increased until serially uncorrelated residual vectors are obtained from each system equation.

As Table 1 reports, the Johansen procedure provides evidence of cointegration among nominal exchange rates and domestic and foreign CPI measures of prices for all countries but Canada, Germany, Denmark, Norway, Switzerland, and Finland. Weak PPP is therefore supported for the majority of countries under the current float. Absolute PPP, given by the restriction $\beta^{\prime}=(1,1,-1)$ (symmetry and proportionality), is strongly rejected for all countries for which a cointegrated system is obtained except Italy.

Using the WPI measures for prices, Table 2 reports that weak PPP is supported for all countries but Canada, Japan, Sweden, and Greece. The jointly applied proportionality and symmetry restrictions are strongly rejected in all countries for which exchange rates and prices form a cointegrated system except Norway, for which the corresponding test statistic is marginally insignificant at the five per cent level. The cointegration evidence obtained differs for some countries depending upon whether CPI or WPI measures of prices are used. For Japan, Sweden, and Greece, weak PPP is supported for only CPI measures of prices while for Germany cointegration evidence between exchange rates and prices is obtained only in the case of WPI measures.

In summary, the evidence in favor of mean reversion in U.S. dollar-based PPP deviations series is quite strong for the expanded sample period studied here. Furthermore,

Phillips-Perron tests. Consistent with the literature, the null hypothesis of a single unit root cannot be rejected. To conserve space these results are not reported here but are available upon request.

14 The multivariate Schwarz information criterion (SIC) was also employed but it generally underestimated the VAR lag length, resulting in serially correlated residual vectors from the system equations. 
this evidence is obtained from single countries' time series, without resorting to the panel methodology which makes use of the cross-sectional variation in the data. This evidence is consistent with the view that the failure to detect convergence to parity in shorter samples may be attributable to the volatile behavior of the U.S. dollar in the 1980 s. $^{15}$

\subsection{Tests for nonlinearity}

Table 3 presents the results of testing for nonlinearity via artificial regression (4) including the delay order chosen by the sequence of tests as providing the strongest evidence. The nonlinearity tests and subsequent analysis are applied to the series of deviations from PPP as estimated by the Johansen method. For convenience, those series will be referred to as real exchange rates hereafter. The length of the autoregression, $p$, for the real exchange rate series is chosen on the basis of the Ljung-Box portmanteau test to ensure absence of residual autocorrelation up to order 24 months. Using a ninety-five per cent criterion, we find that seven of the seventeen trading partners' CPI-based real exchange rates decisively reject the null hypothesis of linearity in favor of the ESTAR specification. For the WPI-based measures, rates for five of the eleven countries reject linearity. This provides clear confirmation that linear cointegration tests may have been weakened by the nonlinear nature of the relationship between elements of the real exchange rate. This is especially true for CPI-based real exchange rates for Germany, Denmark, Norway, and Finland and WPI-based real exchange rates for Japan and Greece, for which no evidence of linear cointegration was found. ${ }^{16,17}$

\footnotetext{
15 Some authors (e.g. Papell and Theodoridis (1998)) argue that the strengthening of the evidence in support of long-run PPP for extended samples is only found when using panel methods but not univariate methods. These studies however impose the symmetry and proportionality restrictions in constructing the deviations series from parity: restrictions clearly rejected by the data.

16 At the five per cent level of significance, the combined evidence (linear as well as nonlinear) suggests that long-run PPP holds true in fourteen (out of seventeen) series based on CPI measures for prices and in seven (out of eleven) series based on WPI measures for prices.

17 If the ESTAR methodology is applied to the real exchange rate series constructed by imposing the unitary vector (strict PPP series), the evidence of nonlinearities found in the deviations series from PPP is confirmed (except for Japan). Additionally, evidence of nonlinear reversion to parity for more countries is obtained when the strict PPP series are considered. This increased evidence of nonlinearities may be the artifact of incorrectly imposing the $(1,1$,
} 
The empirical work proceeds with those real exchange rates for which nonlinear behavior is signalled by the Table 3 test results at the five per cent level. We determine the appropriate specification of the model with a series of sequential hypothesis tests. At the outset, the ESTAR model is estimated, and $H_{0}^{I}: k=k^{*}=c^{*}=0$ is tested. Given a failure to reject those restrictions (which are never rejected by the data), they are imposed, and the model is reestimated. If the joint hypothesis $H_{0}^{I I}: \lambda^{*}=-(1+\lambda)$ (and $\varphi_{j}=\varphi_{j}^{*},(j=1, \ldots, p-1)$, for those models with $\left.p>1\right)$ cannot be rejected, that restriction (or set of restrictions) is imposed as well, and the model is again reestimated. If the hypotheses $H_{0}^{I I I}: \lambda=0$ cannot be rejected, then that restriction is imposed as well, so that the final model for the series is defined by $\gamma$, the parameter of the ESTAR model governing the speed of transition between the two extreme regimes (and possibly on $\left.\varphi_{j}, j=1, \ldots, p-1\right)$. The more stringent restriction that $\lambda=0$ implies the presence of unit-root behavior in the 'middle' regime (when $F(\cdot)=0$ ).

\subsection{Estimation of the ESTAR model}

Table 4 presents summary statistics and residual diagnostics of ESTAR models for seven countries' CPI-based real exchange rates, while Table 5 presents results from five countries' WPI-based real exchange rates. The $\gamma$ estimates vary widely across countries, with the speeds of adjustment for some real exchange rates being much higher than others. Their values generally support the ESTAR model's adequacy, with $\hat{\gamma}$ for most series being clearly distinguishable from zero. For the CPI-based series, the restrictions $H_{0}^{I}$ and $H_{0}^{I I}$ cannot be rejected for any series, so that the estimated models include two for which $H_{0}^{I I I}$ can be rejected: Germany and Finland. For those series, $\hat{\lambda}>0$ (explosive behavior in the middle regime) whereas for all other series, $\hat{\lambda}$ cannot be distinguished from zero (unit-root behavior in the middle regime). For the WPI-based series, $H_{0}^{I I}$ may be rejected for Norway, implying that the process for $y_{t}$ is not white noise in the outer

-1) vector in the construction of the series, a restriction which is clearly rejected by the data. 
regime. However, the stability condition that $\lambda+\lambda^{*}<0$ is satisfied. ${ }^{18}$ For all other series, $\hat{\lambda}$ cannot be distinguished from zero, and the model is essentially defined by $\hat{\gamma}$. It must be noted that evidence of nonlinear dynamic adjustment to PPP as well as the magnitude of the speed-of-adjustment coefficient $\gamma$ for a given country can vary, depending upon the price measure (CPI versus WPI) used in the analysis. Residual diagnostics indicate that the model generates non-autocorrelated errors at the five per cent level for every series studied. ARCH effects are present in one of the CPI-based residual series and in three of the WPI-based residual series. In summary, the ESTAR models appear to provide a clearly acceptable representation for the adjustment process toward PPP for both CPI-based and WPI-based series. Models of linear adjustment may be rejected for the majority of series originally considered, and for many of those series, the ESTAR model provides a superior alternative.

Based on the empirical estimates, the behavior of deviations from long-run PPP can be summarized as follows. In the middle regime $(F(\cdot)=0)$, deviations from parity persist due to unit-root behavior (explosive behavior for the CPI series for Germany and Finland and the WPI series for Norway). In the outer regime $(F(\cdot)=1)$, deviations from parity die out quickly due to their "whiteness." The degree to which deviations from long-run PPP dissipate is increasing in their magnitude. There is a significant degree of persistence (before eventual mean reversion occurs) in the outer regime only in the case of Norway's WPI deviations series.

Panels (a) through (g) of Figure 1 graph the estimated transition functions for the CPIbased deviations series, while panels (a) through (e) of Figure 2 graph these functions for the WPI-based deviations series. These figures confirm the nonlinearity of the series and the appropriateness of the exponential transition function. The range of the transition function values indicates that convergence to long-run PPP is very slow. Additionally, a comparison of the values of the transition parameter $\hat{\gamma}$ obtained here with those reported

18 The hypothesis $H_{0}: \lambda+\lambda^{*}=0$ results in an $F(1,263)=9.168$ with a marginal significance level of 0.002 . However, the evidence for Norway should be interpreted with caution, as none of the crucial coefficients $(\hat{\gamma}, \hat{\lambda}$, and $\hat{\lambda}^{*}$ ) are individually statistically significant. 
in Michael et al. (1997) suggests that the persistence of deviations from parity is much stronger in the post-Bretton Woods era than in the interwar period (the 1920s) or in the two-century span 1802-1992 included in their study.

\subsection{Generalized impulse response functions ${ }^{19}$}

To obtain further insights into the dynamic structure of real exchange rates, we perform impulse response function analysis to evaluate the propagation mechanism of shocks to the real exchange rate process. Unlike a linear model, impulse response functions for a nonlinear model are characterized by dependence on initial conditions (history or path dependence) and the size and sign of the innovation (shock dependence. or asymmetry). Following Koop et al. (1996), the impulse response function can be expressed as the difference between two conditional first-moment profiles:

$$
G I_{X}\left(h, v_{t}, \omega_{t-1}\right)=E\left[X_{t+h} \mid v_{t}, \omega_{t-1}\right]-E\left[X_{t+h} \mid \omega_{t-1}\right]
$$

where $G I_{X}$ is the generalized impulse response function of a variable $X, h$ is the forecasting horizon, $v_{t}$ is the perturbation to the process at time $t, \omega_{t-1}$ is the conditioning information set at time $t-1$ (reflecting the history or initial conditions of the variable), and $E[\cdot]$ is the expectations operator. The expression in (6) provides a natural way of measuring the effect of the shock on the conditional mean of the process.

We produce impulse response functions by estimating $E[\cdot]$ corresponding to a representative (average) history or initial conditions vector. Setting the conditioning vector to $\omega_{t-1}^{0}=E\left[\omega_{t-1}\right]$ ensures that the vector of initial conditions "...lies near the center of the data where the conditional density is most precisely estimated" (Gallant et al., (1993), p. 887). ${ }^{20}$ The conditional forecasts are simulated realizations obtained by iterating the

\footnotetext{
19 This section was included at the suggestion of an anonymous referee.

20 An alternative strategy of estimating generalized impulse response functions for a nonlinear model involves estimating $E[\cdot]$ for each history $\omega_{t-1}$ and then average the obtained sequences over all possible drawings from $\omega_{t-1}$. Given nonlinearities, the impulse response functions derived by these alternative strategies are not expected to be the same.
} 
time series model, randomly drawing with replacement from the estimated residuals of the model, and then averaging over the number of random draws (see Koop et al.(1996) for a detailed description of this methodology). For our real exchange rate series, we derive impulse response functions by setting $h=0,1,2, \ldots, 120$ months and averaging the conditional forecast for each forecasting horizon over 5,000 draws.

The panels in Figure 3 display the cumulative impulse response functions for the levels of CPI-based and WPI-based real exchange rate series corresponding to perturbations in the vector of initial conditions by $+/-1 \%$ and $+/-2 \%$. The particular sort of nonlinearity assumed in the use of the ESTAR framework is scale asymmetry: a larger deviation from PPP should have a more than proportional effect on the model's dynamic path relative to a smaller innovation. In interpreting the dynamic response sequences of the deviations series from PPP, it must be kept in mind that the chosen AR and delay-parameter structures for our ESTAR series (see Table 3) are generally of high order, giving rise to rather complex nonlinear dynamic behavior.

An inspection of the generalized impulse response functions reveals the presence of significant nonlinearities in the dynamic response of real exchange rates to innovations. The following general observations are in order:

i) Shocks of differing magnitude (e.g. $1 \%$ versus $2 \%$ ) have disproportionate effects. The dynamic structure of the series is characterized by scale asymmetry (asymmetry based on the size of the shock). ${ }^{21}$ As mentioned earlier, such behavior is a feature of the ESTAR model.

ii) Positive and negative shocks of the same magnitude appear to have differential dynamic effects (in absolute value terms), thus suggesting sign asymmetry (asymmetry

\footnotetext{
We have also produced estimated IRFs from this strategy (results available on request). The qualitative features of their dynamic behavior do not vary significantly from those estimated from the representative history vector, although there are quantitative differences in their time response for several real exchange rate series.

21 Scale asymmetry for the generalized IRFs can be evaluated by computing a series $A_{h}=G I_{X}(2)_{h}-2 G I_{X}(1)_{h}$ where $G I_{X}(2)_{h}$ and $G I_{X}(1)_{h}$ are the generalized IRFs for a $+2 \%$ and $+1 \%$ innovation, respectively. For a linear IRF (such as that derived from a standard VAR model) the $A_{h}$ series would be zero at all $h$. The degree to which $A_{h}$ differs from zero indicates the magnitude of nonlinear effects in the estimated ESTAR models. Graphs of the $A_{h}$ series (available upon request) indicate that for most of the 12 models considered, sizable deviations from zero are apparent in these measures of scale asymmetry.
} 
based on the sign of the shock). ${ }^{22}$ The observed sign asymmetry may be indicative of more complex nonlinear dynamics than that captured by the estimated ESTAR models.

iii) In most cases, innovations to the process appear to die out, suggesting mean reversion. However, the speed of dissipation and degree of persistence vary considerably across series and shocks to the series.

The WPI-based real exchange rate series for Norway exhibits long-run explosive dynamics. This arises since, based on the $\hat{\lambda}$ and $\hat{\lambda}^{*}$ coefficient estimates reported in Table 5 , this series is characterized by explosive behavior in the middle regime and near-unit-root behavior in the outer regime. Such behavior leads to significant instability in the dynamic structure of the series, as exhibited by the estimated impulse response sequences.

Although the combined evidence from the generalized impulse response functions may be difficult to interpret and generalize, it is clearly indicative of the presence of severe nonlinearities in the dynamic structure of the real exchange rate series. These nonlinearities call into question the results of many studies which have been generated conditional on the adequacy of a linear dynamic structure for real exchange rate series.

\section{Conclusions}

Earlier studies have had difficulty detecting convergence to long-run PPP in the postBretton Woods era, thus suggesting the absence of a link between nominal exchange rates and prices in open economies. Perhaps the well-known weaknesses of unit-root tests in temporally limited samples may account for the prevalence of unit-root findings and the seeming rejection of long-run PPP. Recently, the panel unit-root literature has provided one avenue by which data from this limited temporal span may be used to detect convergence. In contrast, our findings demonstrate that the evidence in favor of PPP markedly strengthens when Johansen's cointegration framework is applied to this expanded sample

22 This asymmetry is apparent if the absolute magnitude of impulse responses to a positive and negative shock of equal magnitude are compared. 
period from the current float, without resort to the cross-sectional variation in the data upon which the panel framework relies. Moreover, by allowing for the presence of nonlinearities in the dynamic adjustment to deviations from PPP in an ESTAR framework, our study provides additional evidence of a mean-reverting dynamic process for sizable deviations from PPP in several countries' series, with an equilibrium tendency varying with the magnitude of disequilibrium. Evidence from generalized impulse response functions also supports the presence of nonlinearities. This evidence of nonlinear adjustment to parity is in contrast to the negative evidence obtained by O'Connell (1998b) for panels of real exchange rates in a TAR framework.

Although the unit-root hypothesis may be rejected for a number of the PPP deviations series, a shock to these series dies out very slowly. Future research may focus on the factors that distinguish those countries whose deviations from long-run PPP are characterized by nonlinear behavior, as well as those related to this unusually slow speed of adjustment. The high volatility of the nominal exchange rate for the U.S. dollar in the 1980s may provide an explanation for the latter.

\section{Acknowledgements}

We are grateful to Peter Pedroni and Nikolay Gospodinov for their useful suggestions, and to participants in the CEFES'98 conference for their comments on an earlier draft. Two anonymous reviewers of this journal provided a very useful critique of the paper. The standard disclaimer applies. 


\section{References}

Balke, N., Fomby, T., 1997. Threshold cointegration. International Economic Review $38(3), 627-645$.

Cheung, Y.-M., Lai, K., 1993. Long-run purchasing power parity during the recent float. Journal of International Economics 34, 181-192.

Coleman, A.M., 1995. Arbitrage, storage and the "Law of one price": New theory for the time series analysis of an old problem. Unpublished working paper, Princeton University, Princeton NJ.

Corbae, D., Ouliaris, S., 1988. Cointegration and tests of purchasing power parity. Review of Economics and Statistics 70, 508-511.

Diebold, F. X., Husted, S., Rush, M., 1991. Real exchange rates under the gold standard. Journal of Political Economy 99, 1252-1271.

Dumas, B., 1992. Dynamic equilibrium and the real exchange rate in a spatially separated world. Review of Financial Studies 5 (2), 153-180.

Edison, H. J., Fisher, E.O., 1991. A long-run view of the European monetary system. Journal of International Money and Finance 10, 53-70.

Engel, C., Hendrickson, M., Rogers, J., 1997. Intra-national, intra-continental and intra-planetary PPP. National Bureau of Economic Research, Cambridge MA. Working Paper 6069.

Engle, R. F., Granger, C.W.J., 1987. Co-integration and error correction: representation, estimation, and testing. Econometrica 55, 251-276.

Fisher, E., Park, J., 1991. Testing purchasing power parity under the null hypothesis of cointegration. Economic Journal 101, 1476-1484.

Frankel, J. A., Rose, A., 1996. Mean reversion within and between countries: A panel project on purchasing power parity. Journal of International Economics 40, 209-224.

Froot, K. A., Rogoff, K., 1995. Perspectives on PPP and long-run real exchange rates. In: Grossman, G., Rogoff, K. (Eds.), Handbook of International Economics. NorthHolland, Amsterdam. Chapter 32. 
Gallant, R., Rossi, P., Tauchen, G., 1993. Nonlinear dynamic structures. Econometrica $61,871-907$.

Goldberg, L.G., Gosnell, T.F., Okunev, J., 1997. Purchasing power parity: Modeling and testing mean reversion. Journal of Banking and Finance 21, 949-966.

Granger, C.W.J., Teräsvirta, T. 1993. Modelling nonlinear economic relationships. Oxford University Press, Oxford, UK.

Grilli, V., Kaminsky, G., 1991. Nominal exchange rate regimes and the real exchange rate. Journal of Monetary Economics 27, 191-212.

Higgins, M., Zakrajsek, E., 1999. Purchasing power parity: Three stakes through the heart of the unit root null. Federal Reserve Bank of New York, New York, NY. Research Paper \#80.

Johansen, S., 1988. Statistical analysis of cointegrating vectors. Journal of Economic Dynamics and Control 12, 231-254.

Johansen, S., Juselius, K., 1990. Maximum likelihood estimation and inference on cointegration-With applications to the demand for money, Oxford Bulletin of Economics and Statistics 52, 169-210.

Koop, G., Pesaran, M.H., Potter, S., 1996. Impulse response analysis in nonlinear multivariate models. Journal of Econometrics 74, 119-147.

Li, K., 1999. Testing symmetry and proportionality in PPP: A panel data approach. Journal of Business and Economic Statistics 17 (4), 409-418.

Liu, P., Maddala, G.S., 1996. Do panel data cross-country regressions rescue purchasing power parity (PPP) theory? Unpublished working paper, Department of Economics, The Ohio State University, Columbus OH.

Lothian, J., 1997. Multi-country evidence on the behavior of purchasing power parity under the current float. Journal of International Money and Finance 16, 19-35.

Lothian, J., 1998. Some new stylized facts of floating exchange rates. Journal of International Money and Finance 17, 29-35.

Meese, R. A., Rogoff, K.S., 1988. Was it real? The exchange-rate interest differential 
relation over the modern floating rate period. Journal of Finance 43, 933-948.

Michael, P., Nobay, A. R., Peel, D.A., 1997. Transactions costs and nonlinear adjustment in real exchange rates: An empirical investigation. Journal of Political Economy $105(4), 862-879$.

Obstfeld, M., Taylor, A., 1997. Nonlinear aspects of goods-market arbitrage and adjustment: Heckscher's commodity points revisited, Journal of the Japanese \& International Economies 11 (4), 441-479.

O'Connell, P. G., 1998a. The overvaluation of purchasing power parity. Journal of International Economics 44, 1-19.

O'Connell, P. G., 1998b. Market frictions and real exchange rates. Journal of International Money and Finance 17, 71-95.

O'Connell, P. G., Wei, S., 1997. 'The bigger they are, the harder they fall': How price differences across U.S. cities are arbitraged. National Bureau of Economic Research, Cambridge MA. Working Paper 6089.

Oh, K.-Y., 1996. Purchasing power parity and unit root tests using panel data. Journal of International Money and Finance 15, 405-418.

Osterwald-Lenum, M., 1992. A note with quantiles of the asymptotic distribution of the maximum likelihood cointegration rank test statistics. Oxford Bulletin of Economics and Statistics 54, 461-472.

Papell, D., 1997. Searching for stationarity: Purchasing power parity under the current float. Journal of International Economics 43, 313-332.

Papell, D., Theodoridis, H., 1998. Increasing evidence of purchasing power parity over the current float. Journal of International Money and Finance 17, 41-50.

Patel, J., 1990. Purchasing power parity as a long run relation. Journal of Applied Econometrics 5, 367-379.

Pedroni, P., 1995. Panel cointegration: Asymptotic and finite sample properties of pooled time series tests with an application to the PPP hypothesis. Unpublished working paper 95-013, Department of Economics, Indiana University, Bloomington IN. 
Pedroni, P., 1997. Fully modified OLS for heterogeneous cointegrated panels and the case of purchasing power parity. Unpublished working paper 96-020, Department of Economics, Indiana University, Bloomington IN.

Reimers, H.E., 1992. Comparisons of tests for multivariate cointegration. Statistical Papers 33, 335-359.

Reinsel, G.C., Ahn, S.K., 1992. Vector autoregressive models with unit roots and reduced rank structure: Estimation, likelihood ratio tests, and forecasting. Journal of Time Series Analysis 13, 353-375.

Rogoff, K., 1996. The purchasing power parity puzzle. Journal of Economic Literature 34, 647-668.

Sercu, P., Uppal, R., Van Hull, C., 1995. The exchange rate in the presence of transaction costs: Implications for tests of purchasing power parity. Journal of Finance 50, 1309-1319.

Taylor, A., 1996. International capital mobility in history: Purchasing-power parity in the long run. National Bureau of Economic Research, Cambridge MA. Working Paper 5742 .

Taylor, M., 1988. An empirical examination of long run purchasing power parity using cointegration techniques. Applied Economics 20, 1369-1381.

Taylor, M., Sarno, L., 1998. The behavior of real exchange rates during the postBretton Woods period. Journal of International Economics 46, 281-312.

Teräsvirta, T., 1994. Specification, estimation and evaluation of smooth transition autoregressive models. Journal of the American Statistical Association 89 (425), 208218.

Tong, H., 1993. Non-linear time series: A dynamical system approach. Oxford Science Publications, Oxford UK.

Uppal, R., 1993. A general equilibrium model of international portfolio choice. Journal of Finance 48, 529-553.

Wu, Y., 1996. Are real exchange rates nonstationary? Evidence from panel-data tests. 
Journal of Money, Credit, and Banking 28, 54-63. 
Table 1. Johansen Cointegration Results for the PPP Hypothesis, CPI-based Measures

Trace Test Statistic

\begin{tabular}{lllllll} 
Country & $k$ & $H_{0}: r \leq 2$ & $H_{0}: r \leq 1$ & $H_{0}: r=0$ & \multicolumn{1}{c}{$\beta^{\prime}$} & $H_{0}: \beta^{\prime}=(1,1,-1)$ \\
Canada & 12 & 2.622 & 12.505 & 24.425 & $(1,-0.810,0.763)$ & - \\
Germany & 10 & 0.420 & 3.974 & 14.936 & $(1,-2.700,0.668)$ & $\overline{ }$ \\
United Kingdom & 13 & $6.769^{*}$ & $21.389^{* *}$ & $62.223^{* * *}$ & $(1,18.938,-26.080)$ & $36.577(0.000)$ \\
France & 8 & 1.387 & 9.395 & $37.582^{* * *}$ & $(1,2.566,-2.566)$ & $14.685(0.001)$ \\
Italy & 8 & 5.980 & $15.695^{*}$ & $32.531^{* *}$ & $(1,3.237,-4.805)$ & $3.932(0.140)$ \\
Japan & 13 & 2.988 & 14.602 & $34.256^{* *}$ & $(1,5.127,-4.168)$ & $19.531(0.000)$ \\
Belgium & 13 & 1.814 & $17.552^{*}$ & $37.316^{* * *}$ & $(1,13.375,-10.383)$ & $19.643(0.000)$ \\
Denmark & 8 & 1.655 & 10.859 & 25.962 & $(1,3.004,-1.990)$ & \\
Luxembourg & 7 & 5.875 & $16.155^{*}$ & $51.114^{* * *}$ & $(1,29.130,-20.187)$ & $29.639(0.000)$ \\
Netherlands & 13 & 3.848 & $19.224^{* *}$ & $41.801^{* * *}$ & $(1,5.447,-4.186)$ & $16.437(0.000)$ \\
Norway & 13 & 3.039 & 10.403 & 21.415 & $(1,1.247,-1.482)$ & $\overline{2}$ \\
Sweden & 8 & 3.320 & 9.271 & $29.217^{*}$ & $(1,-3.274,4.510)$ & $17.125(0.000)$ \\
Switzerland & 13 & 0.478 & 12.520 & 27.476 & $(1,-1.967,0.307)$ & - \\
Finland & 13 & 4.096 & 10.310 & 26.333 & $(1,10.912,-16.167)$ & $\overline{2}$ \\
Greece & 13 & 1.423 & 12.138 & $33.584^{* *}$ & $(1,3.630,-9.664)$ & $18.441(0.000)$ \\
Portugal & 9 & 3.703 & $17.251^{*}$ & $39.243^{* * *}$ & $(1,4.704,-9.595)$ & $14.245(0.001)$ \\
Spain & 9 & 5.697 & $16.897^{*}$ & $43.405^{* * *}$ & $(1,7.246,-17.617)$ & $21.585(0.000)$
\end{tabular}

Notes: The system variables are $\left(S_{t}, P_{t}, P_{t}^{*}\right)$, where $S_{t}$ is the logarithm of the foreign price of domestic currency at time $t$ and $P_{t}$ and $P_{t}^{*}$ are the logarithms of the domestic and foreign levels of the consumer price index (CPI), respectively, at time $t$. The $k$ value indicates the order of the vector error correction model (VECM) estimated for each country. The Johansen 
trace test statistics have been modified to account for finite-sample bias, following the correction suggested by Reinsel and Ahn (1992) and Reimers (1992). The asymptotic critical values (without drift in the data generating process), obtained from Osterwald-Lenum (1992), are presented in the following table, in which $p$ is the number of system variables and $r$ is the cointegration rank:

\begin{tabular}{llll} 
& \multicolumn{3}{c}{ Trace } \\
$p-r$ & $1 \%$ & $5 \%$ & $10 \%$ \\
1 & 11.65 & 8.18 & 6.50 \\
2 & 23.52 & 17.95 & 15.66 \\
3 & 37.22 & 31.25 & 28.71
\end{tabular}

The cointegrating vector $\beta^{\prime}$ has been normalized with respect to the nominal exchange rate variable $S$. The LR test statistic for $H_{0}: \beta^{\prime}=(1,1,-1)$ is distributed $\chi^{2}$ under the null hypothesis with two degrees of freedom (marginal significance levels are given in parentheses). $* * *, * *, *$ indicate significance at the one per cent, five per cent, and ten per cent levels, respectively. 
Table 2. Johansen Cointegration Results for the PPP Hypothesis, WPI-based Measures

Trace Test Statistic

\begin{tabular}{lllllll} 
Country & $k$ & $H_{0}: r \leq 2$ & $H_{0}: r \leq 1$ & $H_{0}: r=0$ & \multicolumn{1}{c}{$\beta^{\prime}$} & $H_{0}: \beta^{\prime}=(1,1,-1)$ \\
Canada & 13 & 1.522 & 6.810 & 16.061 & $(1,0.044,0.224)$ & $\overline{2}$ \\
Germany & 8 & 2.208 & $17.072^{*}$ & $45.006^{* * *}$ & $(1,62.110,-36.466)$ & $24.348(0.000)$ \\
United Kingdom & 13 & 3.845 & $15.936^{*}$ & $36.607^{* *}$ & $(1,0.421,-1.474)$ & $17.005(0.000)$ \\
Japan & 13 & 1.034 & 6.664 & 25.766 & $(1,2.488,-1.808)$ & $\overline{1}$ \\
Denmark & 8 & 2.655 & $16.489^{*}$ & $39.966^{* * *}$ & $(1,3.624,-4.273)$ & $13.978(0.001)$ \\
Netherlands & 5 & 4.902 & $15.904^{*}$ & $67.471^{* * *}$ & $(1,-87.865,47.796)$ & $47.331(0.000)$ \\
Norway & 13 & 2.768 & 14.195 & $31.420^{*}$ & $(1,-0.562,0.906)$ & $5.775(0.056)$ \\
Sweden & 13 & 2.171 & 7.097 & 21.860 & $(1,-1.370,2.646)$ & \\
Finland & 11 & 2.010 & 10.300 & $28.868^{*}$ & $(1,-11.639,13.796)$ & $8.233(0.016)$ \\
Greece & 13 & 1.410 & 10.691 & 27.721 & $(1,0.125,1.962)$ & $13.476(0.001)$ \\
Spain & 12 & 4.308 & $15.077^{*}$ & $31.735^{*}$ & $(1,3.693,-5.924)$ & $6.359(0.042)$
\end{tabular}

Notes: The system variables are $\left(S_{t}, P_{t}, P_{t}^{*}\right)$, where $S_{t}$ is the logarithm of the foreign price of domestic currency at time $t$ and $P_{t}$ and $P_{t}^{*}$ are the logarithms of the domestic and foreign levels of the wholesale price index (WPI), respectively, at time $t$. The $k$ value indicates the order of the vector error correction model (VECM) estimated for each country. The Johansen trace test statistics have been modified to account for finite-sample bias, following the correction suggested by Reinsel and Ahn (1992) and Reimers (1992). See notes in Table 1 for additional explanation of the table. 
Table 3. Tests for linearity of the cointegrating regression

\begin{tabular}{lllllll} 
& \multicolumn{3}{l}{ CPI-based deviations } & \multicolumn{3}{c}{ WPI-based deviations } \\
Country & Optimal & $p$ & $P$-value & Optimal d & $p$ & $P$-value \\
Canada & 12 & 1 & 0.187 & 12 & 9 & 0.064 \\
Germany & 12 & 2 & 0.022 & 7 & 10 & 0.002 \\
United Kingdom & 5 & 13 & 0.035 & 12 & 4 & 0.085 \\
France & 2 & 1 & 0.025 & & & \\
Italy & 4 & 2 & 0.002 & & & \\
Japan & 5 & 13 & 0.013 & 12 & 1 & 0.000 \\
Belgium & 1 & 13 & 0.473 & & & \\
Denmark & 4 & 1 & 0.185 & 4 & 1 & 0.019 \\
Luxembourg & 10 & 10 & 0.336 & & & \\
Netherlands & 12 & 10 & 0.226 & 12 & 3 & 0.142 \\
Norway & 12 & 1 & 0.038 & 3 & 1 & 0.006 \\
Sweden & 10 & 3 & 0.407 & 12 & 2 & 0.120 \\
Switzerland & 12 & 2 & 0.076 & & & \\
Finland & 12 & 9 & 0.037 & 2 & 2 & 0.207 \\
Greece & 6 & 13 & 0.305 & 11 & 3 & 0.027 \\
Portugal & 2 & 12 & 0.098 & & & \\
Spain & 10 & 9 & 0.612 & 12 & 2 & 0.133
\end{tabular}

Notes: The tests are performed on the deviations from PPP as estimated by the Johansen method. The optimal $d$ is chosen by minimizing the P-value of the linearity test for the delay parameter $y_{t-d}$ over the range $\{1,12\}$ given the autoregressive order $p$ which was chosen on the basis of serial correlation tests. 
Table 4. Estimates of the ESTAR model for deviations from PPP, CPI-based measures of prices

$\begin{array}{lllllll}\text { Country } & \hat{\gamma} & \hat{\lambda} & \text { S.E.R. } & \text { D.W. } & Q_{6}, & A R C H_{6}, \\ & & & & & \begin{array}{l}Q_{12} \\ A R C H_{12}\end{array} \\ \text { Germany } & 0.0261 & 0.0290 & 0.0347 & 2.00 & 4.20 & 8.33 \\ & (0.009) & (0.016) & & & 7.00 & 14.88 \\ \text { United Kingdom } & 0.0108 & & 0.1156 & 1.98 & 3.54 & 5.00 \\ & (0.002) & & & & 7.28 & 15.06 \\ \text { France } & 0.0150 & & 0.0330 & 2.02 & 4.80 & 2.68 \\ & (0.006) & & & & 7.43 & 4.19 \\ \text { Italy } & 0.0124 & & 0.0351 & 2.01 & 9.16 & 1.58 \\ & (0.006) & & & & 14.13 & 5.90 \\ \text { Japan } & 0.0061 & & 0.0424 & 2.01 & 2.38 & 3.88 \\ & (0.003) & & & & 3.23 & 10.19 \\ \text { Norway } & 0.0133 & & 0.0297 & 1.98 & 9.13 & 9.44 \\ & (0.005) & & & & 13.36 & 16.67 \\ \text { Finland } & 0.0081 & 0.0170 & 0.0660 & 1.99 & 2.00 & 12.86^{* *} \\ & (0.004) & (0.009) & & & 19.15^{*} & 15.84\end{array}$

Notes: The model is applied to the deviations series from PPP as estimated by the Johansen procedure, where the domestic and foreign price levels are measured by the respective CPIs. Standard errors are given in parentheses. S.E.R. is the standard error of regression, while D.W. is the Durbin-Watson test statistic. $Q_{6}, Q_{12}$ are the LjungBox Q statistics for absence of serial correlation up to $6^{\text {th }}$ and $12^{\text {th }}$ order, respectively. $A R C H_{6}, A R C H_{12}$ are tests for ARCH effects up to $6^{\text {th }}$ and $12^{\text {th }}$ order, respectively. ***, $* *, *$ denote significance at the one per cent, five per cent, and ten per cent levels, respectively. 
Table 5. Estimates of the ESTAR model for deviations from PPP, WPI-based measures of prices

\begin{tabular}{|c|c|c|c|c|c|c|c|}
\hline Country & $\widehat{\gamma}$ & $\hat{\lambda}$ & $\hat{\lambda}^{*}$ & S.E.R. & D.W. & $\begin{array}{l}Q_{6} \\
Q_{12}\end{array}$ & $\begin{array}{l}A R C H_{6}, \\
A R C H_{12}\end{array}$ \\
\hline \multirow[t]{2}{*}{ Germany } & 0.0058 & & & 0.2289 & 1.99 & 3.25 & $15.72^{* *}$ \\
\hline & $(0.003)$ & & & & & 17.20 & 15.93 \\
\hline \multirow[t]{2}{*}{ Japan } & 0.0833 & & & 0.0304 & 2.06 & $10.96^{*}$ & $14.86^{* *}$ \\
\hline & $(0.020)$ & & & & & $20.93^{*}$ & 16.10 \\
\hline \multirow[t]{2}{*}{ Denmark } & 0.0138 & & & 0.0391 & 2.17 & 6.28 & 10.09 \\
\hline & $(0.006)$ & & & & & 18.56 & $34.97^{* * *}$ \\
\hline \multirow[t]{2}{*}{ Norway } & 3.6246 & 0.0751 & -0.0883 & 0.0313 & 1.91 & 4.86 & 6.64 \\
\hline & $(2.145)$ & $(0.059)$ & $(0.0$ & & & 11.70 & 11.94 \\
\hline \multirow[t]{2}{*}{ Greece } & 0.0042 & & & 0.0325 & 2.00 & 4.34 & 1.75 \\
\hline & $(0.003)$ & & & & & 11.49 & 6.52 \\
\hline
\end{tabular}

Notes: See notes to Table 4. 
Figure 1: Estimated Transition Functions for CPI-based Deviations
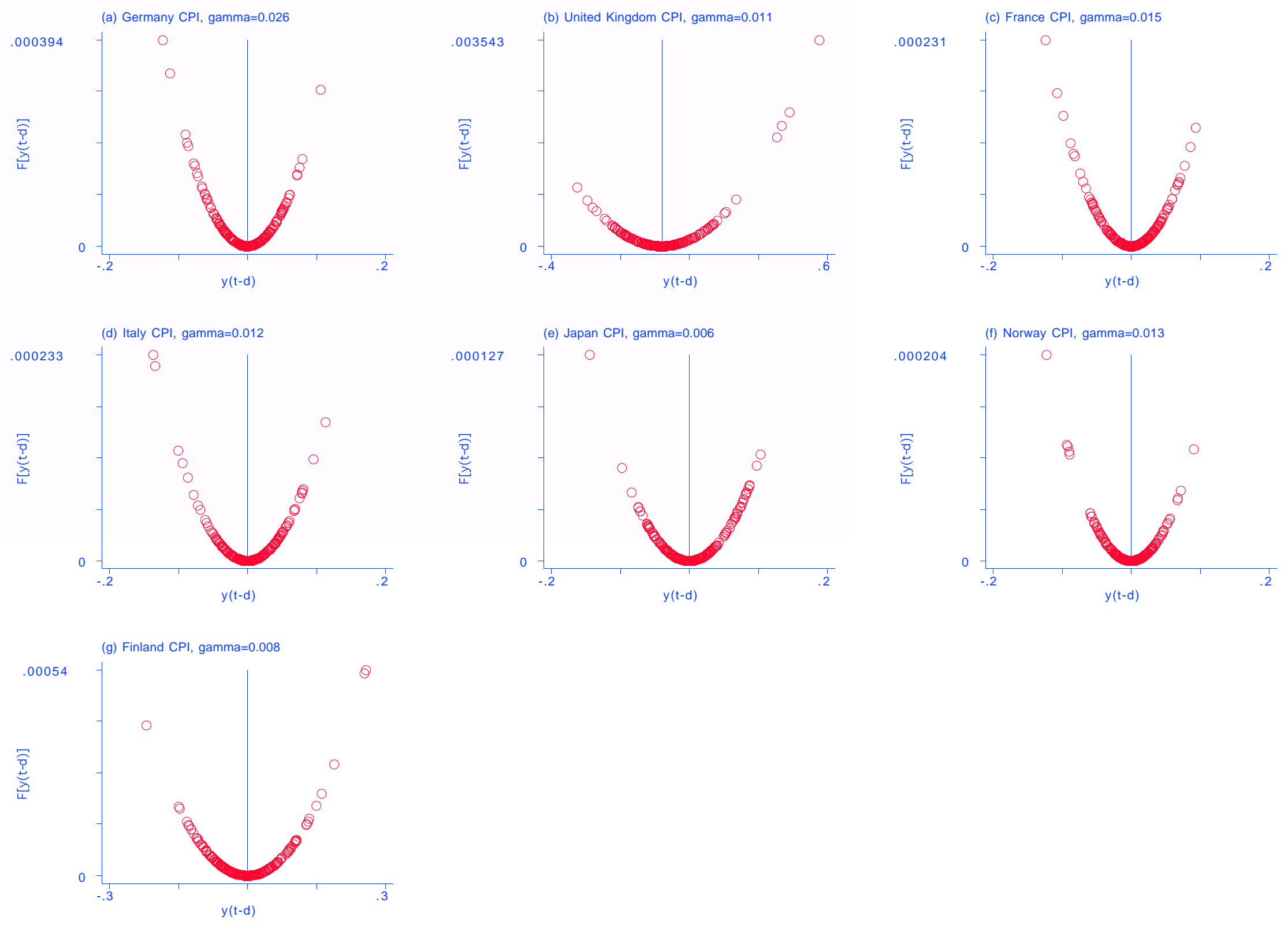
Figure 2: Estimated Transition Functions for WPI-based Deviations
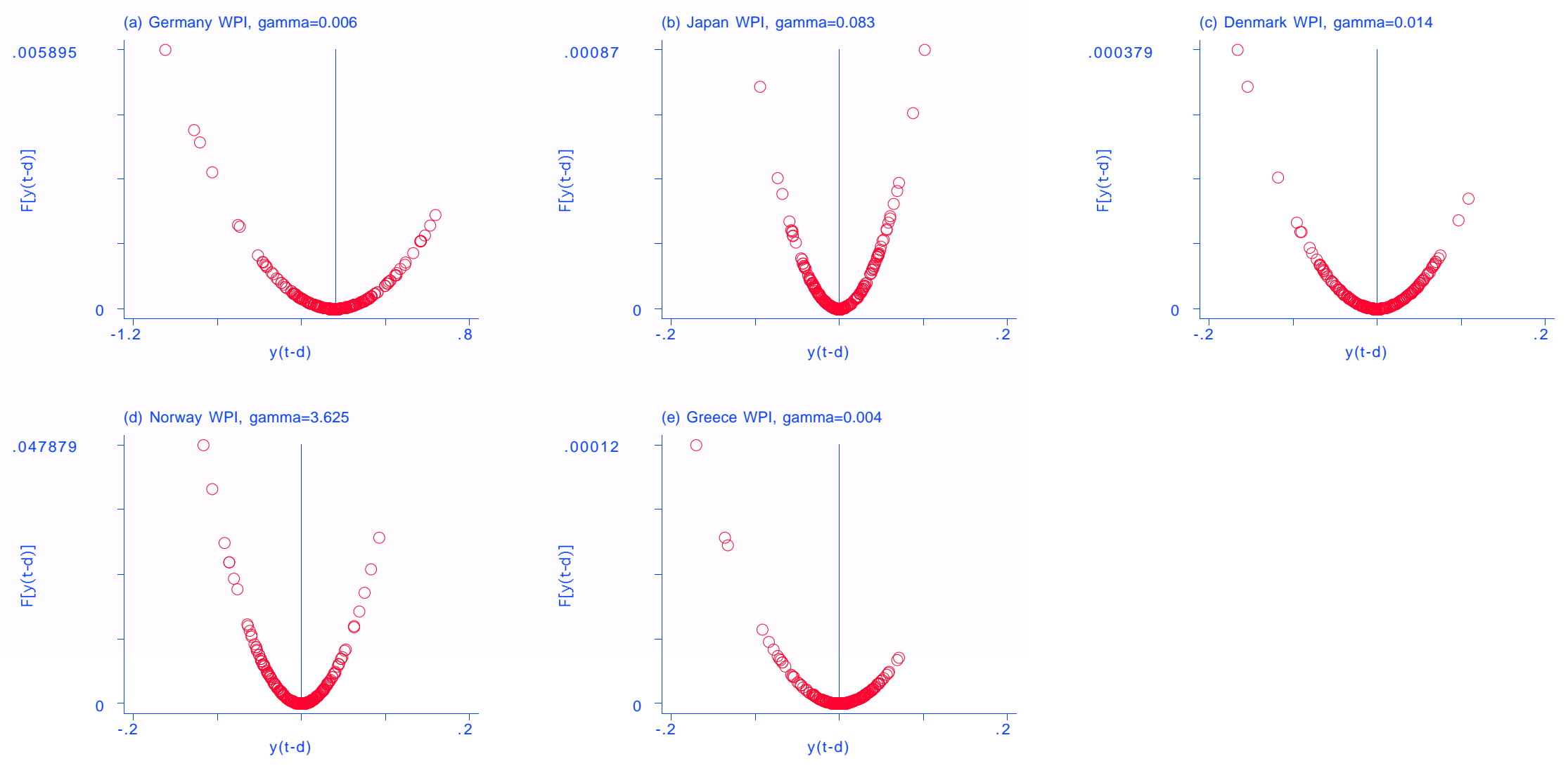


\section{Figure 3}

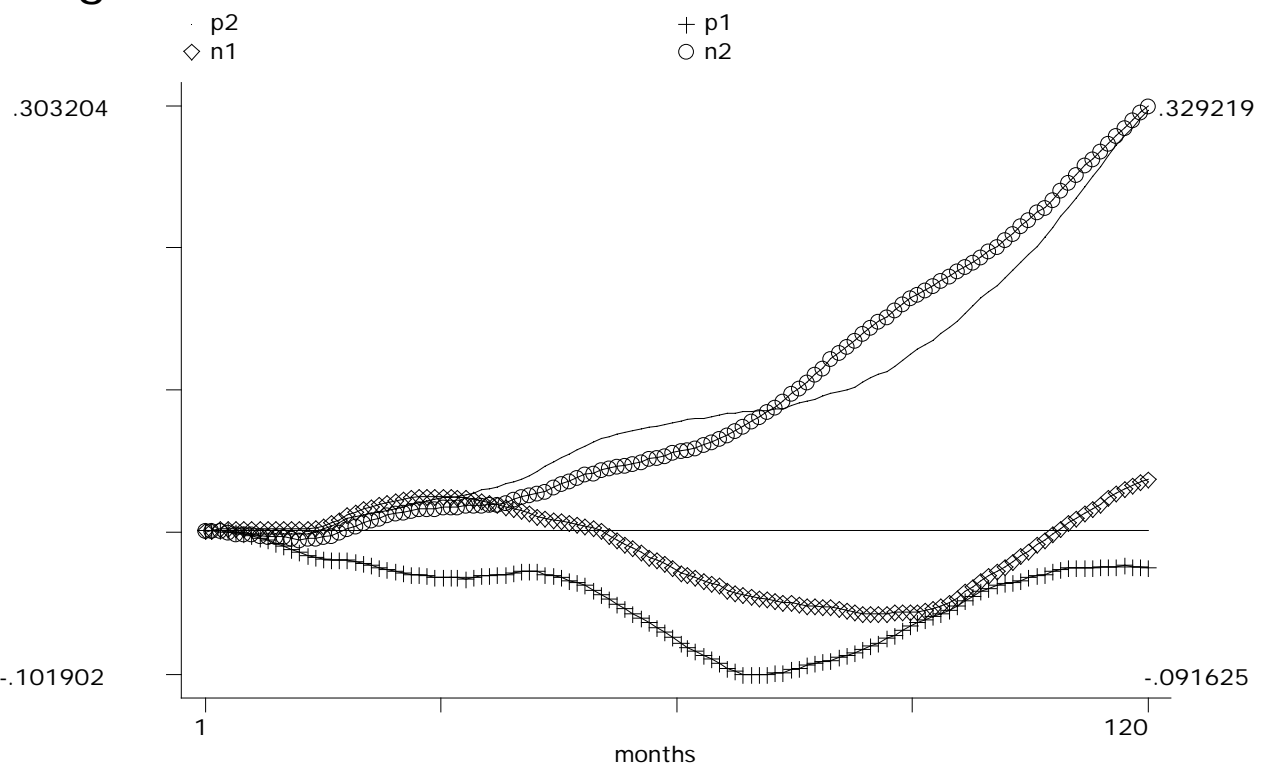

(a) IRFs for Norway CPI

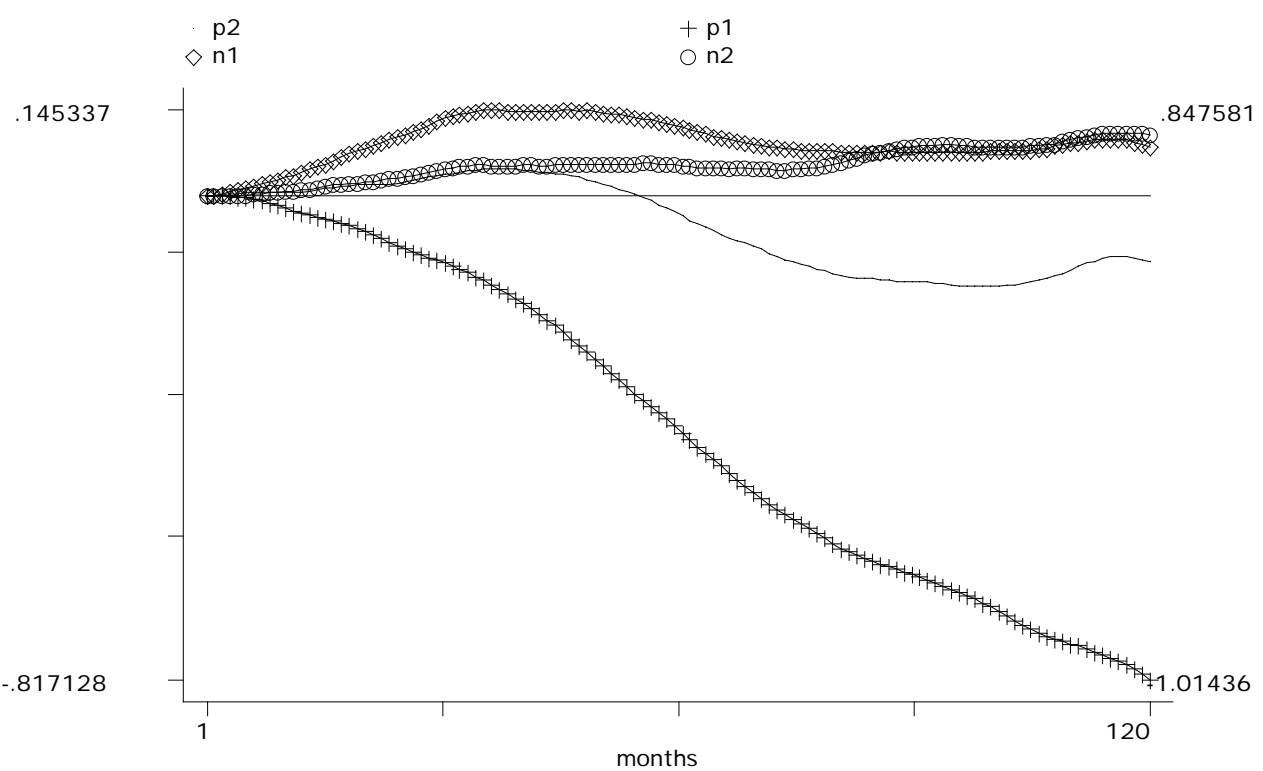

(c) IRFs for Italy CPI

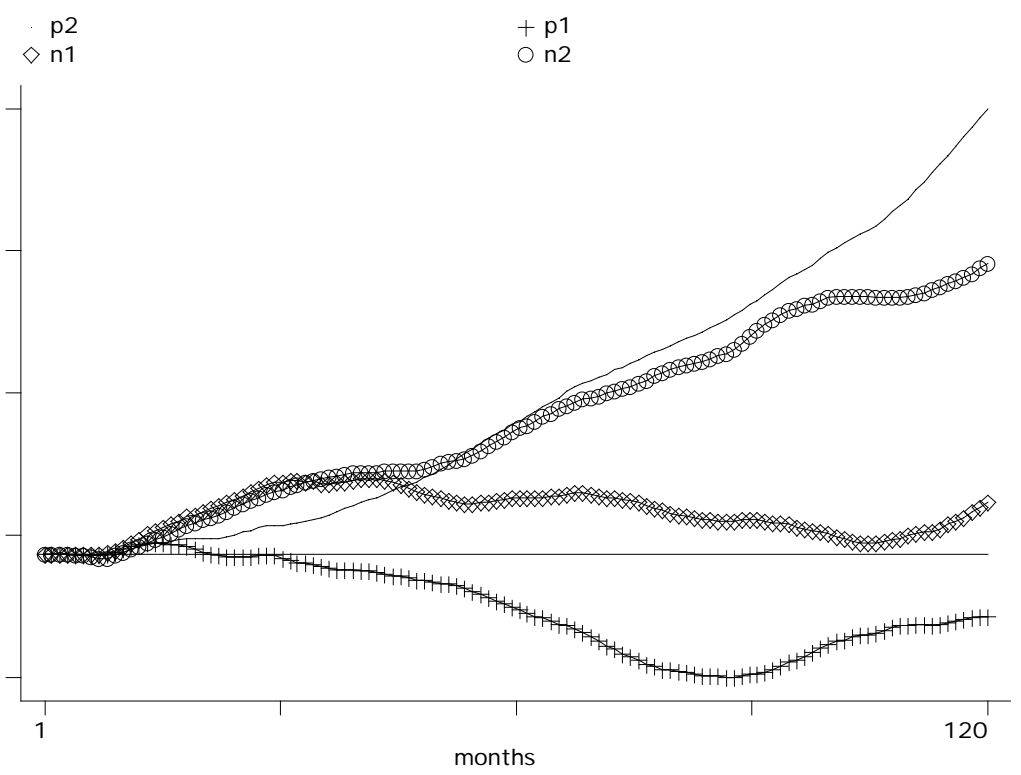

(b) IRFs for France CPI

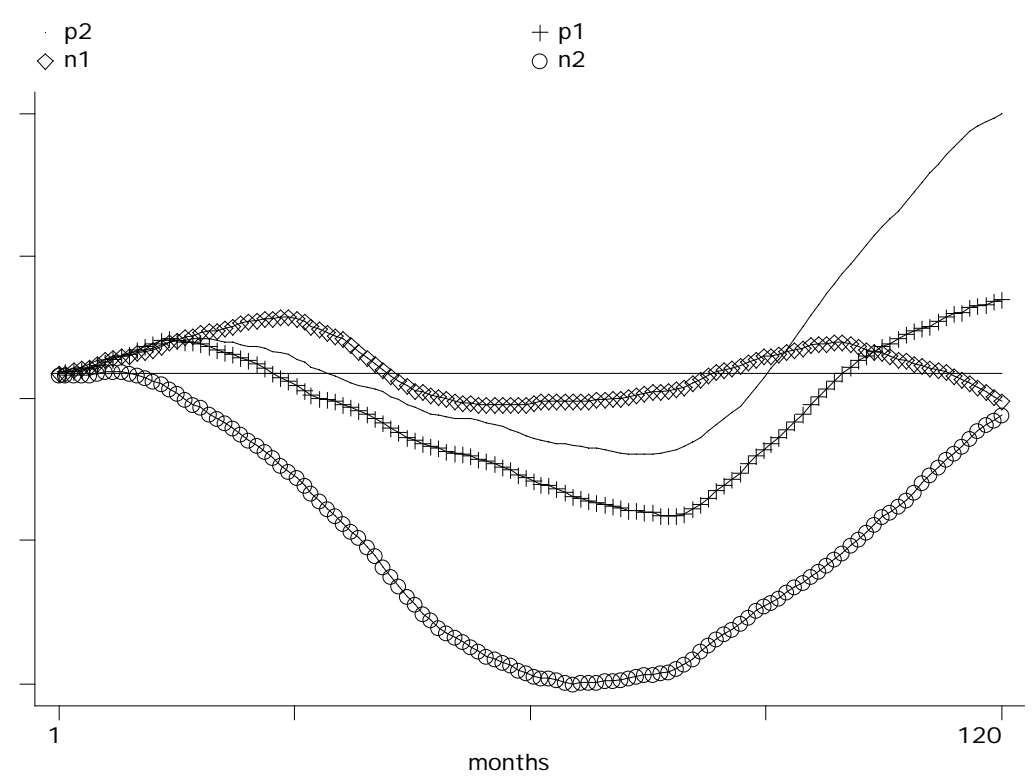

(d) IRFs for U.K. CPI 


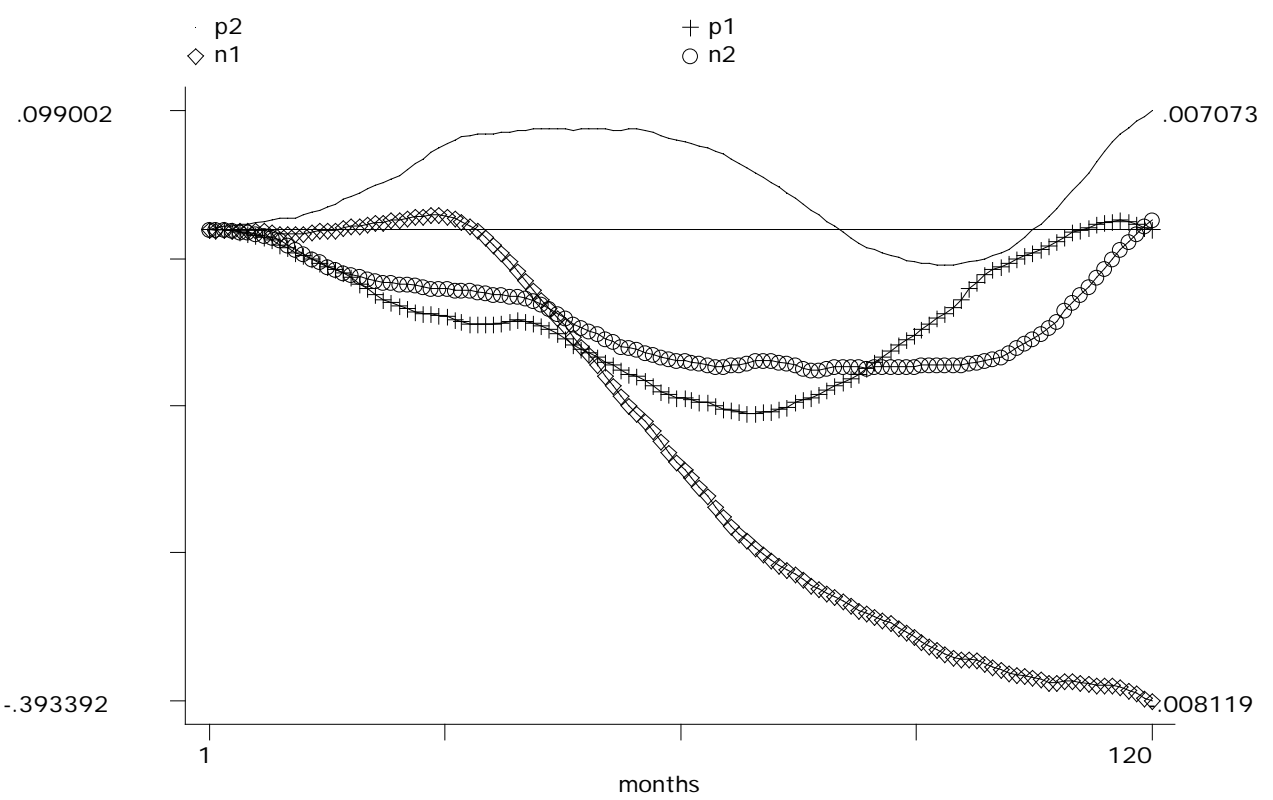

(e) IRFs for J apan CPI
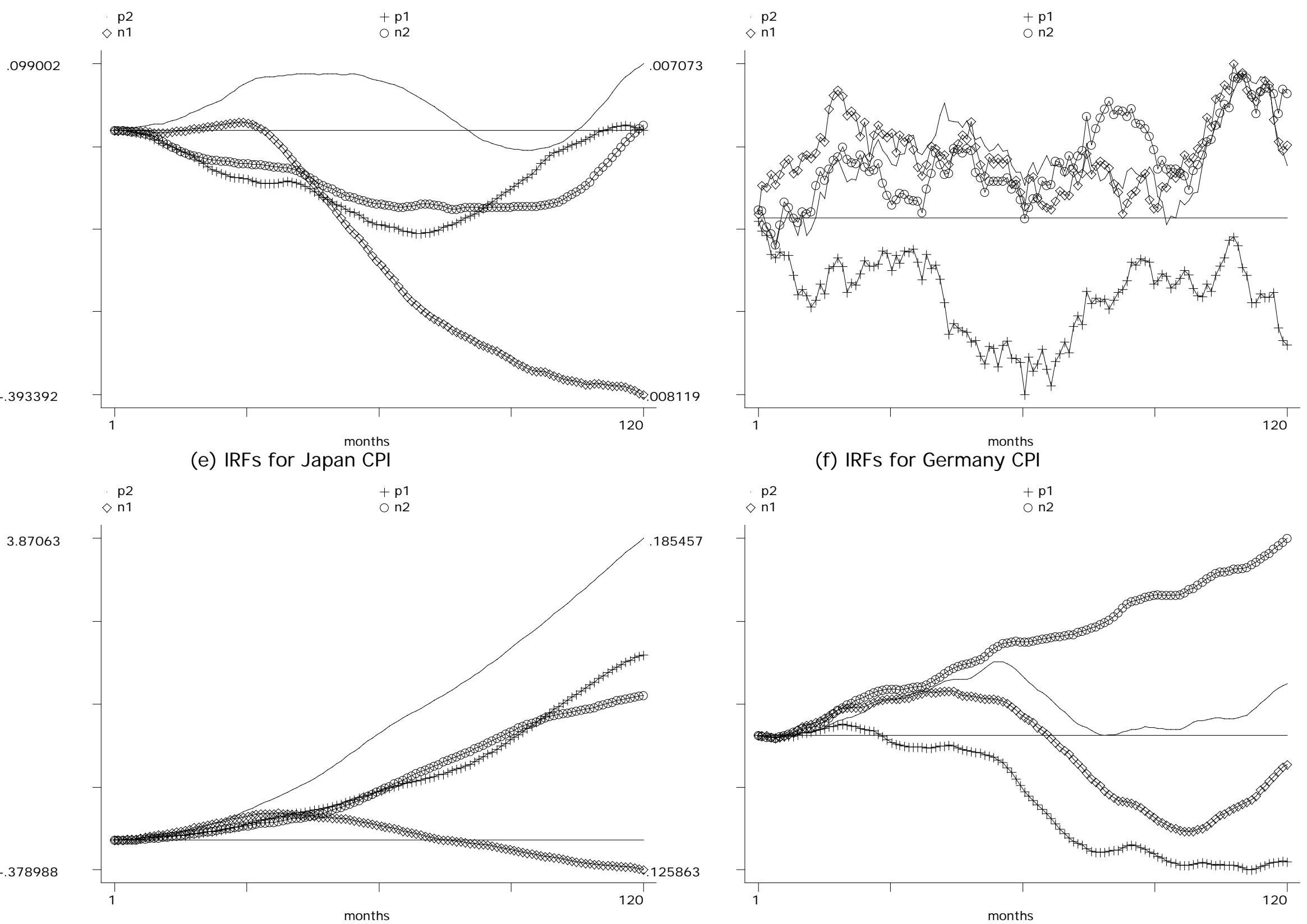

(g) IRFs for Finland CPI

(f) IRFs for Germany CPI

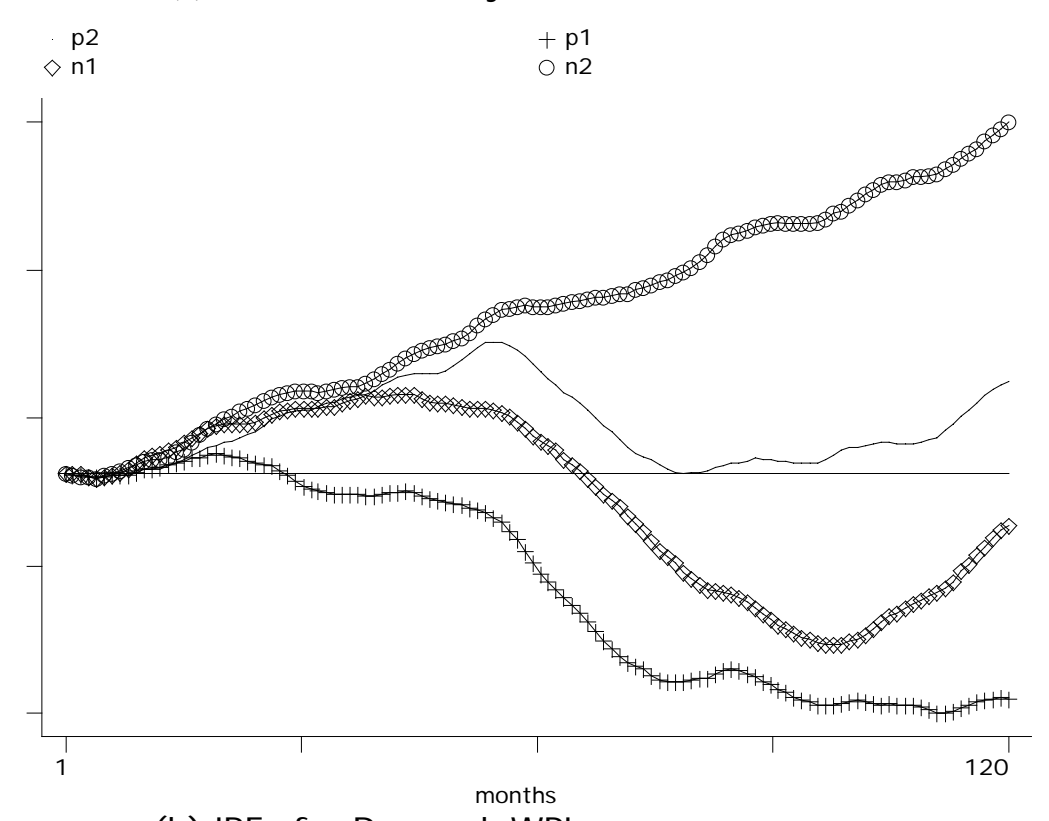

(h) IRFs for Denmark WPI 


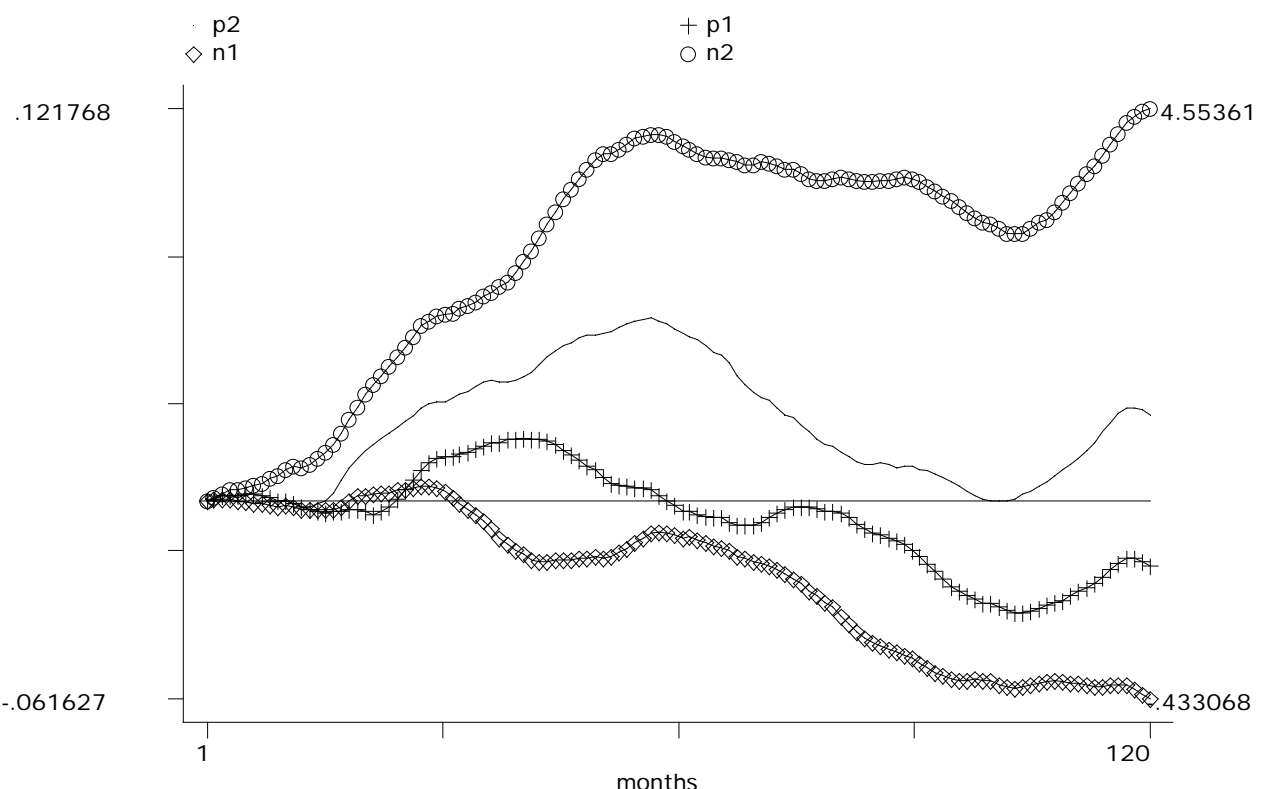

(i) IRFs for J apan WPI

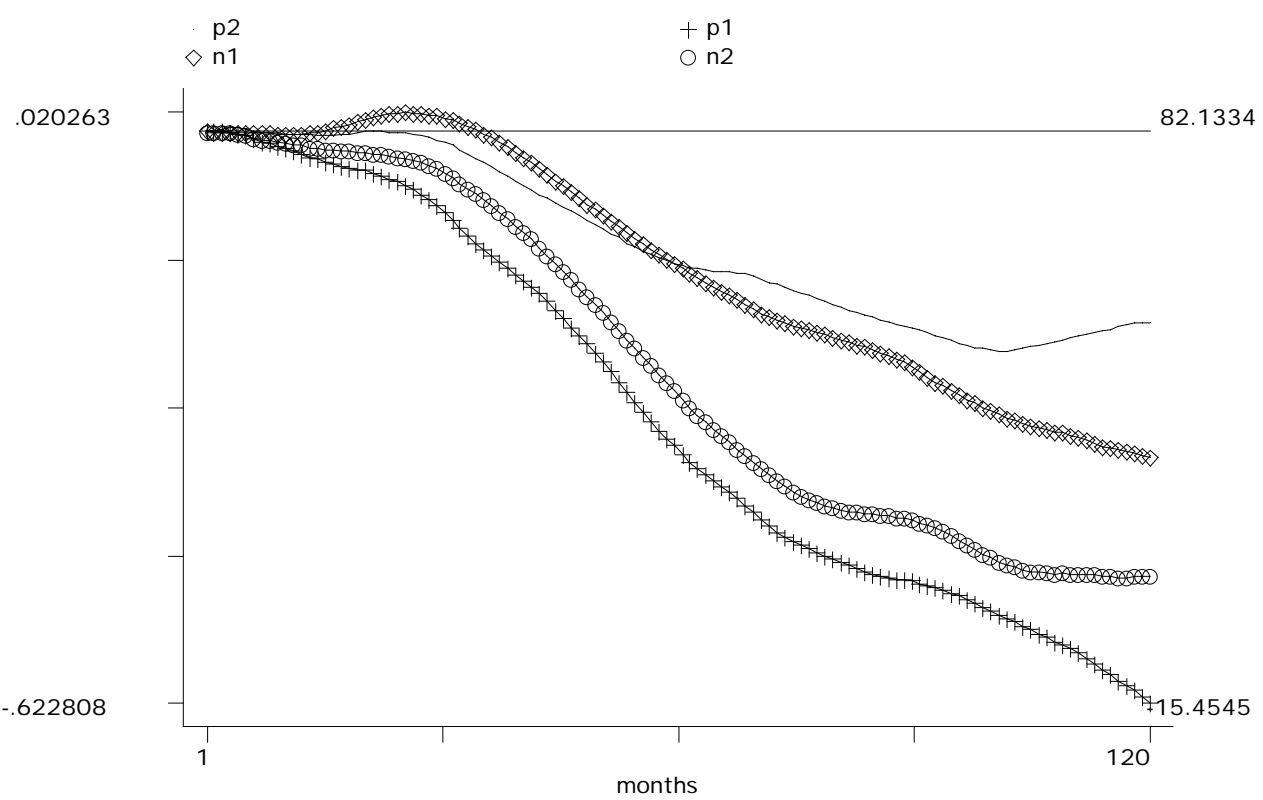

(k) IRFs for Greece WPI

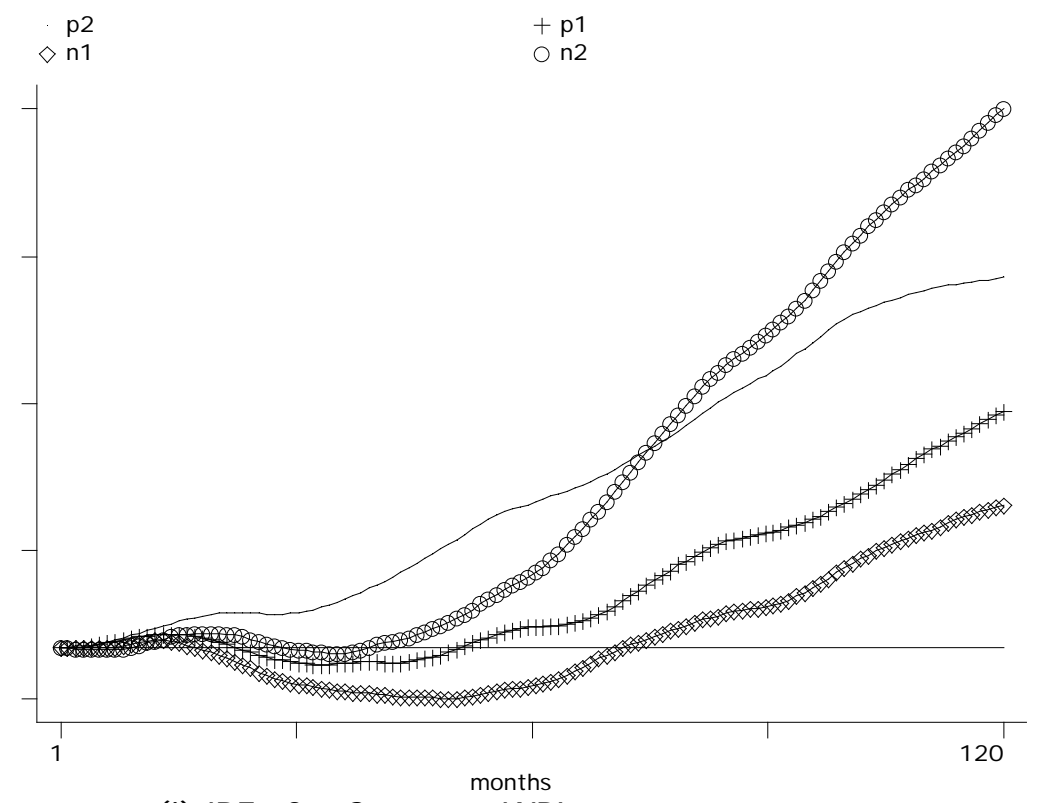

(j) IRFs for Germany WPI

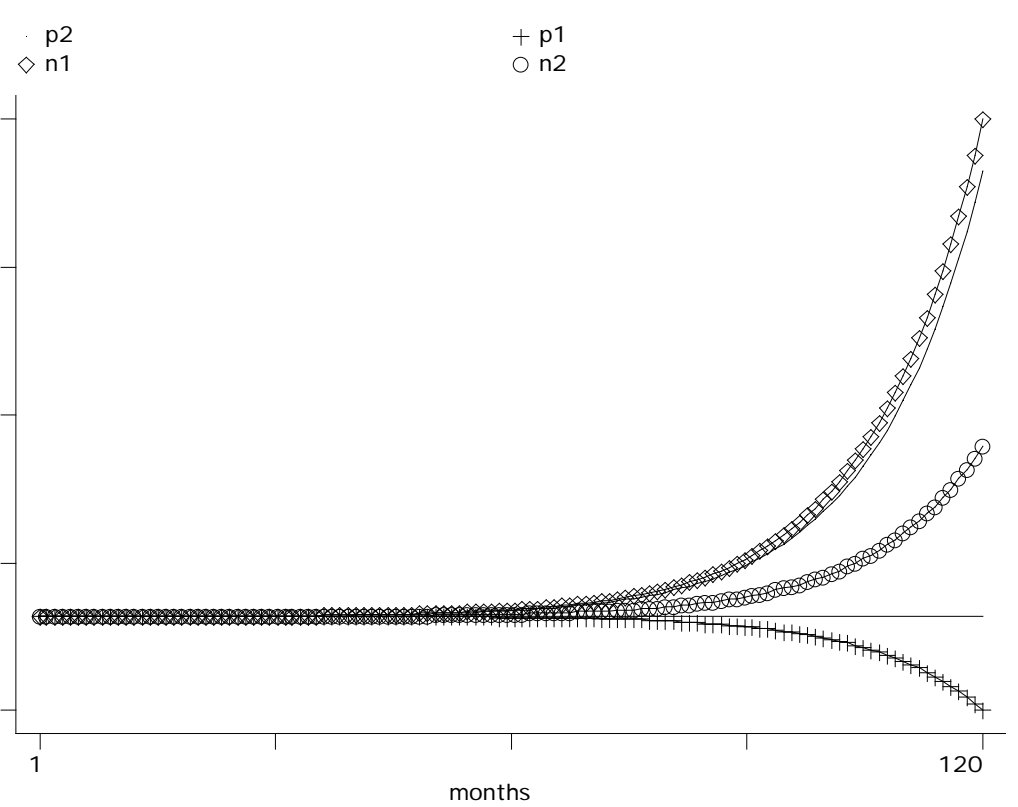

(I) IRFs for Norway WPI 